\title{
Revistas en línea sobre patrimonio cultural en Internet
}

Teresa Abejón

Ángeles Maldonado

CINDOC-CSIC

Es muy difícil en este breve espacio hacer un comentario en profundidad del estado de la publicación en Internet de revistas sobre patrimonio cultural. En líneas generales, en esta disciplina el panorama es tan confuso y poco definido como en el resto de las publicaciones periódicas en línea sobre Ciencias Sociales y Humanidades. Sin abordar los problemas más debatidos en torno a la revista electrónica (gratuidad vs acceso restringido, libre circulación de contenidos vs defensa de los derechos de autor, etc.), en resumen diremos: 1) que todavía existen pocas revistas electrónicas; 2) que en formato electrónico, como en la edición impresa, existe una tipología muy variada que va desde la publicación científica a los boletines de noticias pasando por las revistas de divulgación; 3) que las publicaciones que existen, con excepciones, son versiones en formato digital de las que ya se publicaban en papel; 4) que las revistas exclusivamente digitales, en general, no cumplen los parámetros de calidad que poco a poco se van implantando en las de carácter académico en papel; 5) que los editores aprovechan poco las posibilidades técnicas proporcionadas por el formato electrónico.

Para dar idea del panorama actual, a continuación presentamos las publicaciones relacionadas con el patrimonio cultural más relevantes que se pueden consultar en Internet acompañadas de un breve comentario ${ }^{1}$.

Conservation. The Getty Conservation Institute Newsletter http://www.getty.edu/conservation/resources/newsletter.html El Getty Conservation Institute publica 3 números al año de su Newsletter, que es accesible de forma gratuita. Esta publicación totalmente en formato electrónico ofrece, además de los resultados de los trabajos del propio instituto, otros artículos relacionados con la conservación e interpretación de objetos, colecciones, obras de arquitectura y lugares que forman parte del patrimonio cultural. En el web están disponibles todos los números a partir del volumen 6 (1991).

\section{Journal of Conservation \& Museum Studies http://www.jcms.ucl.ac.uk/}

Sólo en Internet publica el Institute of Archaeology (University College London) esta revista especializada interesante para la comunidad académica internacional relacionada con la conservación y los museos. El acceso a los índices, los resúmenes y el texto completo es gratuito. Hasta ahora se han editado siete números que contienen de dos a cinco artículos muy extensos.

\section{JAIC online \\ http://aic.stanford.edu/jaic/}

Sitio web que da acceso gratuito a los números del Journal of the American Institute for Conservation publicados entre los años 1977 y 2000. Este web funciona como un archivo histórico electrónico de los números publicados por esta revista en el periodo mencionado. El sistema que da acceso a los textos es bastante completo, pues se puede llegar a los mismos a través de los sumarios ordenados por números, de los títulos presentados alfabéticamente y de un formulario de búsqueda donde introducir las palabras clave que definen el tema de interés. Es una pena que los números publicados a partir del año 2000 no estén disponibles en formato electrónico aunque sea bajo suscripción.

\section{PH Boletín del Instituto Andaluz del Patrimonio Histórico http://www.juntadeandalucia.es/cultura/iaph/publicaciones/ form_ibol.html}

El Instituto Andaluz del Patrimonio Histórico da acceso a los indices de toda la revista y ofrece gratuitamente los dossiers temáticos desde el $n^{\circ} 25$ a texto completo en html con una buena presentación. Se trata de un interesante recurso en español para la formación y actualización profesional especializada de los colectivos comprometidos con la conservación, documentación, gestión y difusión del patrimonio.
Journal of Cultural Heritage

http://www.elsevier.com/inca/publications/store/6/2/0/7/3/8/ Publicación trimestral aparecida en el año 2000 cuyo objetivo es editar trabajos estrictamente científicos. Los artículos publicados provienen de diversas disciplinas académicas y tienen el denominador común de presentar nuevas técnicas en la conservación y explotación del patrimonio cultural. Cada número se acompaña de todo tipo de noticias de interés en el plano internacional. Su edición corre a cargo de Elsevier, que pone a disposición en formato electrónico todos los números en su servicio ScienceDirect. Es necesario suscribirse para su uso, pero puede visualizarse gratuitamente un ejemplar completo.

\section{International Journal of Heritage Studies} http://www.tandf.co.uk/journals/routledge/13527258.html Revista publicada por la editorial Routledge con un consejo editorial internacional compuesto por miembros pertenecientes a instituciones académicas y de investigación. Desde una óptica multidisciplinar reúne artículos sobre teoría e historia del patrimonio, técnicas de conservación y restauración, estudios de interpretación y diseño, y artículos sobre cultura y turismo. Pueden consultarse gratuitamente los sumarios a partir del volumen 6 y los resúmenes de los articulos contenidos en dichos números. Es necesario suscribirse para su consulta a texto completo, pero se dispone de un número que sirve de ejemplo.

\section{In situ la revue de l'Inventaire général} http://www.culture.gouv.fr/culture/revue-inv/index.html Únicamente en Internet difunde esta revista gratuitamente la Direction de I'Architecture et du Patrimoine (Ministère de la Culture et de la Communication. Francia). Dos números desde el $\mathrm{n}^{\circ} 1$ de 2001 con un dossier central dedicado a un tema especifico, varios artículos de fondo sobre temas diversos y algunos textos informativos cortos, siempre relacionados con bienes muebles e inmuebles incluidos en el Inventaire général.

\section{Boletín de Interpretación http://www.interpretaciondelpatrimonio.com/}

La página de la Asociación para la Interpretación del Patrimonio, con sede en Pamplona, ofrece acceso gratuito al texto completo de los nueve números de su revista en formato pdf. Es una publicación muy especializada en la comunicación con el público visitante, por lo cual interesa sobre todo a los profesionales de la interpretación del patrimonio (natural y cultural).

\section{Interpretation}

\section{http://www.heritageinterpretation.org.uk/jouridx.html}

Association for Heritage Interpretation ofrece en su sede web los indices completos de los doce números de su revista, así como el texto completo en html de una selección de artículos (de 2 a 5 por número) y de los editoriales. Sus artículos tratan cuestiones de relevancia para los especialistas en interpretación del patrimonio, e interesa especialmente a quienes desarrollan su actividad en el Reino Unido.

\section{Boletín de ICOM-CE}

\section{http://www.icom-ce.org/Portales/portal_boletin.htm}

Cuatro números de este medio de comunicación del Comité Español del Consejo Internacional de Museos, con vocación de vínculo y foro de debate entre los profesionales de los museos españoles, están disponible gratuitamente a texto completo en Internet.

Se puede consultar gratuitamente el texto completo de otras revistas que tienen menor interés como The World Heritage Newsletter, World Heritage Review o Nuestro Patrimonio Histórico. Por otra parte, existen sitios web que ofrecen información sobre revistas no disponibles en línea que incluyen frecuentemente los indices y en ocasiones los resúmenes de los artículos. En esta situación encontramos revistas como Bollettino ICR, Patrimonio Cultural y Derecho, Reales Sitios, Castillos de España, Ars Sacra, etc.

${ }^{1}$ Información relativa a una primera fase de trabajo realizada en septiembre de 2003 